\title{
ERRATA, VOLUME 48
}

M. R. Hestenes, The problem of Bolza in the calculus of variations, pp. 57-75.

p. 63, first display line. Instead of $g(t)$ read $g(a)$.

p. 72 , line 32 . Instead of by $E_{0}^{*}$ the set $\cdots$ read by $\varepsilon_{0}^{*}$ the set....

Isaac Opatowski, Confluent hypergeometric functions and Markoff chains, abstract 48-5-179.

p. 365 , line 2 . Instead of $k_{i}=0$ read $k_{0}=0$.

A. N. Lowan, N. Davids and A. Levenson, Table of the zeros of the Legendre polynomials of order 1-16 and the weight coefficients for Gauss' mechanical quadrature formula, pp. 739-743.

p. 742, last display line. Instead of $x_{k}^{3}$, in the denominator, read $x_{k}+3$. 